\title{
A valorização docente, PSPN e PCCR Um estudo no município de Dourados-MS
}

\author{
Flávia Paula Nogueira Aranda* \\ Simone Estigarribia de Lima** \\ Elisangela Alves da Silva ScafF ${ }^{* * *}$
}

\begin{abstract}
RESUMO: $\mathrm{O}$ artigo versa sobre a valorização do profissional docente no município de Dourados-MS, buscando analisar a política de valorização dos profissionais no contexto atual, enfocando o Plano de Cargos, Carreira e Remuneração e A Lei do Piso Salarial Profissional, em pesquisa qualitativa, em que o corpus documental foi composto por peças nacionais e municipais sobre o tema.
\end{abstract}

Palavras-chave: Salário docente. Política educacional. Plano de carreira.

\section{Introdução}

$\mathrm{E}$ sse estudo é parte das reflexões empreendidas no Programa Institucional de Bolsa de Iniciação Científica (Pibic), articulado ao Grupo de Pesquisa Estado, Política e Gestão da educação (Gepge) da Faculdade de Educação (Faed) da Universidade Federal da Grande Dourados (UFGD).

Tal estudo teve por objetivo apresentar pesquisa tendo como objeto de investigação a valorização do profissional docente no Município de Dourados, Mato Grosso do Sul (MS), tendo como foco os movimentos em torno do plano de carreira e salário docente no momento atual.

* Mestranda em Educação. Membro do Grupo de Pesquisa Estado, Política e Gestão da Educação (Gepge) da Faculdade de Educação (Faed) da Universidade Federal da Grande Dourados (UFGD). Dourados/MS - Brasil. E-mail:<flaviaaranda@hotmail.com>.

* Doutoranda em Educação. Pedagoga no Instituto Federal de Mato Grosso do Sul (IFMS). Integra o Grupo de Pesquisa Gepge/Faed/UFGD. Dourados/MS - Brasil. E-mail: <simoneestilima@gmail.com>.

*** Pós-Doutorado em Educação. Professora adjunta da UFGD atuando no curso de Pedagogia e no Programa de Pós-Graduação em Educação (Mestrado e Doutorado). Coordenadora da Seção MS da Anpae e coordenadora do GT 5 da Anped (Centro-Oeste). Dourados/MS - Brasil. E-mail: <Elis-scaff@hotmail.com>. 
Sendo assim, apresentamos as políticas de valorização docente, apontando como a legislação nacional vem orientando a gestão local, em seguida, analisando ações empreendidas e os embates decorrentes da luta dos profissionais de educação, na busca pela efetivação da valorização docente.

Trata-se de pesquisa qualitativa com suporte de dados quantitativos obtidos no banco de dados na internet do Inepdata. Informações sobre os embates e reivindicações da categoria, obtidos nos jornais locais e no site do sindicato dos professores desse município. O corpus documental foi composto por peças nacionais e municipais que tratam do tema, obtidas nos site do Senado Federal e do Diário Oficial do município. Os dados foram interpretados à luz de estudos bibliográficos.

No contexto da redemocratização ocorrida no Brasil em meados dos anos de 1980 emergem e se estruturam as lutas dos profissionais da educação com a intenção de conquistar novos direitos e melhores garantias para o exercício profissional, sendo que a melhoria da qualidade da educação tem relação direta com o trabalho docente.

Em decorrência, o tema em pauta vem merecendo crescente atenção na agenda das políticas públicas, o que abre perspectivas promissoras para estudos, aprofundamentos e críticas. A amplitude do conceito de valorização docente leva-nos a fazer um recorte analítico, focando dois elementos importantes, a saber: Plano de Cargos, Carreira e Remuneração (PCCR) e Piso Salarial Profissional Nacional (PSPN).

Em relação ao Plano de Cargos e Carreira, a Lei no 9.424 de 24 de Dezembro de 1996, que dispõe sobre o Fundo de Manutenção e Desenvolvimento do Ensino Fundamental e de Valorização do Magistério (Fundef), foi o documento oficial na caminhada para a garantia do direito conforme aponta o art. 9..

Art.9 Os Estados, o Distrito Federal e os Municípios deverão no prazo de seis meses da vigência dessa Lei, dispor de novo Plano de Carreira e Remuneração do Magistério de modo a assegurar:

I-A remuneração condigna dos professores do ensino fundamental público, em efetivo exercício no magistério;

II-O estímulo ao trabalho em sala de aula;

III-A melhoria da qualidade do ensino;

$\S 1^{\circ}$ os novos planos de carreira e remuneração do magistério deverão contemplar investimentos na capacitação de professores leigos, os quais passarão a integrar quadro em extinção, de duração de cinco anos.

$\S 2^{0}$ aos professores leigos é assegurado o prazo de cinco anos para obtenção de habilitação necessária ao exercício das atividades docente (BRASIL, 1996).

Em 20 de Junho de 2007 foi instituída a Lei n⿳ำ 11.494, que regulamenta o Fundo de Manutenção e Desenvolvimento da Educação Básica e de Valorização dos Profissionais 
da Educação (Fundeb) substituindo a Lei no 9.424 (Fundef). Conforme consta em seu art. $2^{0}$ “ [...] os fundos destinam-se à manutenção e ao desenvolvimento da educação básica pública e a valorização dos trabalhadores em educação, incluindo sua condigna remuneração, observado o disposto nesta Lei" (BRASIL, 2007).

Em termos de remuneração, um marco para nossa análise foi a aprovação da Lei n ${ }^{0}$ 11.738, de16 de julho de 2008, que instituiu o Piso Salarial Profissional Nacional para os profissionais do magistério público da Educação Básica. Sua aprovação foi duplamente benéfica, pois, além de instituir um piso nacional, regulamentou a destinação de $1 / 3$ da carga horária de trabalho do professor à realização de atividades como planejamentos, estudos, reuniões, avaliação.

Referente à remuneração do docente, a Lei n⿳0 11.738 representou uma profunda alteração na política salarial dos professores, pois, até então, cada estado e município, além do Distrito Federal e da própria União, tratavam a questão de forma diferenciada, resultando em valores diferenciados pagos aos docentes de todo o Brasil.

A Lei $n^{0}$. 11.738, de 2008 fixou um vencimento mínimo para professores da educação básica com diploma de ensino médio ${ }^{1}$, na modalidade normal, uma carga horária de 40 horas semanais, e estabeleceu que $1 \frac{1}{3}$ da carga horária do trabalho do professor seja destinada ao planejamento das aulas, além da garantia de reajuste salarial anual.

Pelas dimensões continentais do Brasil e sua diversidade, ter uma Lei que regulamenta um piso nacional para professores é de suma importância para a valorização docente, combate a precarização do trabalho e garante uma remuneração mais equitativa, pois nenhum professor poderá receber abaixo do valor estabelecido como piso, assim

Piso é um valor abaixo do qual não poderão ser estabelecidos vencimentos iniciais de carreira. Portanto, um referencial de reconhecimento profissional. Em qualquer lugar do Brasil, a proposta é de que haja um patamar de valorização salarial semelhante a tantos já obtidos por diversas categorias, a exemplo dos militares. Portanto, a questão de mérito é exatamente esta: o Piso implica reconhecimento da profissão (VIEIRA, 2007, p.38).

A falta de implantação imediata do piso ocasionou descontentamento geral por parte dos docentes, uma vez que, para além dos discursos, cujos conteúdos expressam intenções eleitoreiras, na prática muito pouco tem sido feito pela valorização do magistério.

Gatti (2012) sinaliza que, em termos salariais, a profissão docente está entre as menos valorizadas, pois a profissão não é atrativa e não dá oportunidade de ascensão social e cultural. Assim, a questão salarial envolve debates intensos e se destaca como tema da política educacional, pois, além de incentivo à profissão, o salário deve constituir-se em oportunidade de crescimento profissional e pessoal.

A contribuição específica da investigação pautou-se na seguinte problemática: Como está sendo implementada a política de valorização docente referente a remuneração e carreira profissional no município de Dourados? 
Responder a essa pergunta foi de fundamental importância para identificar e analisar a política de valorização dos profissionais da educação no Município de Dourados, MS, especialmente no que se refere a Lei Complementar n⿳ำ 118 que dispõe sobre o Plano de Cargos, Carreira e Remuneração (PCCR) do profissional docente municipal e ao Piso Salarial Profissional Nacional (PSPN).

\section{O contexto do município de Dourados (MS)}

Dourados é o segundo maior município do estado do Mato Grosso do Sul e possui aproximadamente 210.870 mil habitantes segundo dados do Instituto Brasileiro de Geografia e Estatística (IBGE 2015). Situado na região Centro-Oeste, próximo à divisa com o estado do Paraná e próximo à fronteira com o Paraguai. Possui área territorial de 4.096,90 $\mathrm{km}^{2}$, sendo 40,68 km² de área urbana. O município tem como fonte de renda agricultura, pecuária e comércio local. Em 2010, Dourados obteve 0,747 no Índice de Desenvolvimento Humano (IDH-M), o terceiro melhor índice do estado (ATLAS BRASIL, 2010).

Dourados possuía, em 2012 (último levantamento), 1.894 docentes na educação infantil e ensino fundamental e 514 no ensino médio. O ensino médio é ofertado somente pela rede estadual, em 187 escolas $^{2}$. Os dados incluem profissionais e instituições da rede pública e privada (IBGE, 2012).

Embora a cidade de Dourados seja uma das maiores do estado e com condições de vida favoráveis, segundo seu IDH-M, quando se trata de remuneração dos professores do magistério público municipal, o cenário não é animador. De acordo com um ranking da remuneração docente, elaborado pelo Sindicato Municipal dos Trabalhadores em Educação de Dourados (Simted) e divulgado em nota no site oficial da instituição, dos 79 municípios de Mato Grosso do Sul, Dourados está em 46º lugar, ou seja, mais da metade dos municípios do estado pagam melhor seus professores (Simted, 2016).

A qualidade da educação e a valorização dos professores (as) devem caminhar junto e o piso salarial se insere como fator fundamental de valorização, uma vez que o salário é garantia de sustento material. Como definido por Vieira, o piso salarial tem por finalidade

[...] remunerar dignamente os profissionais do magistério. Um salário adequado concorre para a construção da imagem profissional e confere aos educadores um sentido de pertencimento social, indispensável para que os mesmos possam contribuir para a construção de uma sociedade mais igualitária (VIEIRA, 2013, p.42).

Com o reajuste salarial de $11,36 \%$ no início de 2016, o valor do piso salarial no município de Dourados passou a ser R 3.286,32 (três mil, duzentos e oitenta e seis reais e trinta e dois centavos) para uma jornada de 40 horas de trabalho semanais, valor que se 
aplica ao professor da educação infantil e anos iniciais do ensino fundamental formado em nível superior, em início de carreira, conforme Lei Complementar $n^{0} 313$ de 29 de Março de 2016, que dispõe sobre o reajuste salarial referente ao ano de 2016.

Cabe esclarecer que, embora a Lei do Piso seja de 2008, Mato Grosso do Sul e seus municípios só começaram a cumpri-lo após 2011, quando julgada sua constitucionalidade. Isso sinaliza a falta de prioridade com a categoria docente, tendo em vista ser o segundo maior município do Estado em arrecadação.

A luta da categoria no município é para que o PSPN seja pago para uma jornada de 20 horas. Atualmente, o valor corresponde a 40 horas de trabalho semanal, ou seja, luta-se por uma redução da jornada de trabalho sem redução salarial. Essa discussão está em pauta desde 2014, quando a categoria deflagrou greve, que durou em média três semanas, sendo necessária a mediação de representantes da Câmara de Vereadores e do Ministério Público. para que pudessem chegar a um acordo e retomar as atividades.

Diante do exposto, o acordo firmado estabeleceu a redução gradual da jornada de trabalho num período de quatro anos, tendo início em 2016, para garantir o valor do piso de 40 horas semanais com a redução para uma jornada de trabalho de 20 horas, conquista de alguns municípios sul-mato-grossenses, como o caso da capital do Estado, Campo Grande.

Tal acordo foi firmado pela Lei Complementar nํ267, de 17 de dezembro de 2014, que "Dispõe sobre a política salarial para os profissionais do magistério municipal na forma que menciona e dá outras providências", e publicado em Diário Oficial no dia 08 de janeiro de 2015 (DOURADOS, 2014).

Nele, foram firmadas as seguintes propostas: Em relação ao piso de 20 horas será incorporado na data de $1 .^{\circ}$ de abril de 2016 (data base de reajuste salarial da categoria no município), a concessão do índice de correção do piso salarial para os profissionais do magistério público da Educação Básica ( já em vigor, conforme anteriormente a L.C. $n^{0}$ 313), sendo dois acréscimos anuais, em outubro de 2016 e em outubro de 2020, quando finalmente, o valor do PSPN municipal corresponderá ao PSPN para uma jornada de 20 horas semanais. Por ora, a categoria segue aguardando o cumprimento do acordo firmado.

A Lei do piso sem dúvidas foi uma conquista que não aconteceu sem lutas no município de Dourados, mesmo com a aprovação em âmbito nacional. $\mathrm{O}$ engajamento dos profissionais da educação e seu sindicato foi de fundamental importância para a conquista, principalmente no que se refere à redução da jornada de trabalho sem prejuízo à remuneração. Contudo, ainda cabe acompanhar como se dará essa implementação. 


\section{Estatuto do Plano de Carreira: o desafio a ser cumprido}

Embora explicitado na forma de Lei, a remuneração digna e as melhorias na qualidade profissional docente vêm sendo foco das lutas e movimentos travados, de um lado, por parte da classe trabalhadora, de outro, por parte dos órgãos públicos responsáveis pelo cumprimento da Lei.

A Lei nº 11.494 (Fundeb 2007), em seus artigos 40 e 41, confirmam o compromisso com a valorização dos profissionais do magistério, responsabilizando estados e municípios na elaboração de planos de carreira e remuneração docente:

Art. 40 Os estados, o Distrito Federal e os municípios deverão implantar Planos de Carreira e remuneração dos profissionais da educação básica, de modo a assegurar:

I-a remuneração condigna dos profissionais na educação básica da rede pública;

II- integração entre o trabalho individual e a proposta pedagógica da escola;

III- a melhoria da qualidade do ensino e da aprendizagem;

Parágrafo único. Os Planos de Carreira deverão contemplar capacitação profissional, especialmente voltada a formação continuada com vistas na melhoria da qualidade do ensino.

Art. 41 O poder público deverá fixar, em lei específica, até 31 de agosto de 2007, piso salarial profissional nacional para os profissionais do magistério público da educação básica (BRASIL, 2007).

O Plano de Carreira Docente como cargo efetivo traz segurança para o profissional, porém, na diversidade do contexto brasileiro, percebemos ainda muita desigualdade em relação ao cumprimento dos dispositivos legais, como a ausência de planos ou planos aprovados, mas não executados.

E, ainda, sendo reafirmado no vigente Plano Nacional de Educação, Lei no 13.005 (PNE 2014-2024), incorporando o PSPN nos planos de cargos e carreiras, conforme aponta a Meta 18:

Meta 18: assegurar no prazo de 2 (dois) anos, a existência de planos de carreira para os (as) profissionais da educação básica e superior pública de todos os sistemas de ensino, e para o plano de carreira dos (as) profissionais da educação básica pública, tomar como referência o piso salarial nacional profissional, definido em lei federal, nos termos do inciso VIII do art.206 da Constituição Federal (BRASIL, 2014).

Em Dourados, o primeiro documento produzido para reger o magistério público municipal foi o Estatuto do Magistério público Municipal de Dourados, aprovado pela Lei n⿳ำ 1412, de março de 1987. Elaborado por uma comissão específica, institui regras 
para carreira, ingresso, concurso, nomeação, progressão funcional, exercício, lotação, remoção, jornada e regime de trabalho, direitos, licenças, vencimentos, vantagens, contratação e enquadramento do pessoal do magistério (DORTA, s/d).

Segundo a autora, esse documento refletiu uma importante conquista para professores e especialistas na área da educação, pois garantiu segurança e incentivo para o aperfeiçoamento profissional.

De 1987 até o momento, a Lei que rege o magistério público municipal passou por reformulações, sendo a mais recente, a de 2007, pela Lei Complementar n⿳ํㅜ118, de 31 de dezembro, que aprovou o Plano de Carreira e Remuneração do Profissional Docente (PCCR), do município de Dourados, o qual “Dispõe sobre o plano de cargos, carreiras e remuneração do Profissional da Educação Municipal de Dourados-MS dá outras providâncias" (DOURADOS, 2007).

E em seu Art. $1^{\circ}$ esclarece que " [...] essa Lei complementa a Lei de Diretrizes e Bases da Educação Nacional (LDBEN); Lei Federal nº 11.494, de 20 de junho de 2007 e Lei Orgânica do município", estabelecendo normas especiais sobre o seu regime jurídico e ainda, [...] "que compete à Secretaria Municipal de Educação aplicar as disposições desta lei e, no que couber, articular-se para sua execução com a Secretaria Municipal da Gestão Pública" (DOURADOS, 2007, p.1).

Em seus Artigos 2ํㅜ e $3^{\circ}$ afirmam, respectivamente, que o objetivo e finalidade da Lei Complementar $n^{0}$ 118, é estruturar e organizar os cargos em carreira e democratizar as oportunidades de crescimento funcional incentivando a qualificação do servidor docente no município de Dourados.

$\mathrm{O}$ artigo $4^{\circ}$ do PCCR do município define os princípios básicos dos profissionais da educação municipal como sendo necessário:

a. Qualidades individuais, formação e atualização que garantam resultados positivos ao Sistema Municipal de Ensino;

b. Remuneração que assegure situação condigna nos planos econômicos e sociais;

c. Existência de condições ambientais de trabalho pessoal, de apoio qualificado, instalações e materiais didáticos adequados;

d. Retribuição salarial baseada na habilitação, independente da área de atuação da REME (DOURADOS, 2007, p.5).

A carreira profissional do magistério municipal, conforme o PCCR municipal (2007, p.6), se dá nas "Seguintes funções de docência; direção escolar; professor coordenador; professor de sala de tecnologias educacionais; professor inspetor pedagógico; professor de educação especial; professor de educação agropecuária; e professor intérprete". 
O grupo ocupacional do magistério público municipal é composto pela categoria funcional de professor; especialista em educação com nível de escolaridade superior com licenciatura plena, distribuídos em quatro níveis de escolaridade, sendo eles:

Nível I- habilitação específica obtida em curso superior, com licenciatura plena ou equivalente, nos termos da Lei;

Nível II- escolaridade específica obtida em curso de pós-graduação, em nível de especialização, com duração de carga horária mínima de 360 (trezentos e sessenta horas);

Nível III- escolaridade específica em curso de pós-graduação, obtida em nível de mestrado;

Nível IV- escolaridade específica em curso de pós-graduação, obtida em nível de doutorado (DOURADOS, 2007, p.8).

Ainda em termos de categoria funcional, o documento cita em seu artigo $6 . \stackrel{\circ}{\text { inciso }}$ 1. o oito classes de progressão designadas na forma de letras sendo elas A, B, C, D, E, F, $\mathrm{G}$ e $\mathrm{H}$, sendo a classificação A para professor docente em início de carreira e letra H para profissional do magistério acima de vinte anos de atuação.

A promoção ou elevação do profissional da educação municipal à classe seguinte se dará em duas situações: tempo de serviço ou merecimento, a cada 03 (três) anos, por meio da apuração anual de desempenho profissional na classe ou ao completar 05 (cinco) anos na mesma classe $\backslash$ letra.

Em termos de remuneração e os incentivos financeiros e $\backslash$ ou gratificações, a Lei Complementar nº 118 (PCCR-Dourados) deixa claro, em seu artigo 40, as condições específicas exigidas como garantia direito, destacamos algumas:

I-ao Profissional do Magistério Municipal, Gratificação pelo efetivo exercício no Ensino Fundamental do Profissional do Magistério, na alfabetização de $1 .^{\circ} \mathrm{e} 2 . .^{\circ}$ ano, $10 \%$ (dez por cento);

II-ao Profissional da Educação Municipal, gratificação pelo exercício em escola de difícil acesso ou provimento;

III-ao profissional do Magistério Municipal pelo efetivo exercício noturno a partir das 18 horas, $10 \%$ (dez por cento);

IV- ao Profissional do Magistério Municipal, pela efetiva regência em classe de salas multisseriadas, $15 \%$ (quinze por cento);

VIII-incentivo pró-funcionário de $5 \%$ ao servidor administrativo que comprovar a participação em curso técnico específico da Educação, através de certificado reconhecido pela Secretaria Municipal de Educação e mediante requerimento (DOURADOS, 2007, p.27).

O documento aponta no artigo 13 os critérios para ingressar no magistério público municipal por meio do concurso público de provas e títulos, trazendo em seu inciso 2. ${ }^{\circ}$ 
a validade do concurso por dois anos, podendo ser prorrogado por mais dois anos. No entanto, esse é um dos direitos negligenciado, motivo de intenso descontentamento por parte da categoria, que reivindica constantemente seu cumprimento.

Somente com a pressão do sindicato local e intervenção judicial, a gestão municipal lançou o edital do concurso para provimento de cargos do magistério público municipal em 05 de Fevereiro de 2016, cuja prova escrita ocorreu em 10 de Abril de 2016. O resultado oficial ainda não foi divulgado.

Entretanto, mesmo após a realização da prova, há intensos debates e questionamentos, pois como o concurso apenas se efetivou diante da ação judicial. O edital não possui informações claras quanto à divulgação do resultado, datas para nomeação, prova de títulos e posse. Enfim, todas essas indagações causam insegurança quanto a efetivação do concurso, correndo o risco de ser até mesmo cancelado.

Em 2011, devido à necessidade de reformulações no PCCR, foi composta uma comissão, pelo Sindicato Municipal dos Trabalhadores em Educação de Dourados, para debater pontos relacionados à valorização dos trabalhadores e trabalhadoras em educação. Dentre as exigências, cabe destacar: a elevação por merecimento e dos níveis de escolaridade; a ampliação das classes de promoção na carreira; a redução da jornada de trabalho sem redução salarial; a criação de novas funções, conforme a necessidade; dentre outras.

As reivindicações foram colocadas em pauta, porém, com a denúncia de corrupção e cassação do prefeito na época, as propostas do plano não foram debatidas, sendo também negligenciada pela atual administração municipal, configurando-se, assim, numa das necessidades em caráter de urgência a reformulação imediata do PCCR municipal. Atualmente, essa reformulação está em andamento, o que somente foi possível atendendo a uma das metas reivindicadas no Plano Municipal de Educação (PME 2015-2025).

O documento mais recente que trata de política educacional no município é a Lei Complementar no 3.904 de 23 de Junho de 2015, que "Aprova o Plano Municipal de Educação de Dourados-MS e dá outras providências", com vigência decenal, atendendo ao cumprimento do disposto no art. 214 da Constituição Federal, do art.194 da Constituição Estadual, do art. 8.ำ da Lei Federal nº 13.005 (PNE) e a Lei Estadual nํ 4.621(PEE-MS), apontando no art. $2^{\circ}$ a valorização dos profissionais da educação como uma das diretrizes.

Por se tratar de um plano decenal, a partir de sua aprovação, em junho de 2015, a maioria das estratégias ainda não foi cumprida, porém cabe destacá-la, a começar pelas estratégias 15.5 e 15.12, atendendo a meta 15 do PME, que trata da formação do profissional do magistério:

15.5 fomentar políticas específicas para a formação inicial e continuada de profissionais da educação para atuarem nas escolas do campo, das comunidades indígenas, quilombolas, e para a educação especial contemplando todas as etapas e modalidades da educação básica, na vigência deste PME; 
15.12 incentivar por meio de regime de colaboração entre União, Estado e Município, que os docentes da educação infantil e de ensino fundamental tenham formação específica de nível superior, de licenciatura plena e em sua área de concurso \atuação (DOURADOS, 2015 p.35).

A lei traça estratégias claras e objetivas, considerando o contexto municipal e regional, que, se forem cumpridas, com certeza trarão melhorias significativas à educação pública municipal, como apontam a da meta 16 do PME, que trata da formação em nível de pós-graduação de 50\% (cinquenta por cento) de professores da educação básica. Dentre as estratégias, destacamos:

16.7 garantir para todos os profissionais de educação, licenciamento remunerado e $\backslash$ ou bolsa para cursos de mestrado e doutorado, com cota de $1 \backslash 8$ (um oitavo) dos profissionais para afastamentos, bem como horário reservado para estudos, a partir do primeiro ano de vigência deste PME (DOURADOS,2015, p.38).

No tocante à meta 17 do PME, a cargo da remuneração docente, as estratégias são as seguintes:

17.1 constituir fórum específico, em âmbito municipal, com representações dos órgãos públicos, dos trabalhadores da educação e de segmentos da sociedade civil para acompanhamento da atualização do valor do piso salarial nacional, para os profissionais do magistério público da educação básica e dos repasses financeiros, na vigência deste PME;

17.2.1 implantar, no mínimo, piso nacional do magistério para uma jornada semanal de 20 (vinte) horas, por meio de uma política salarial que inicie em 2016 e finalize em 2020, conforme Lei Complementar n.267 de 17 de Dezembro de 2014; respeitando a lei de responsabilidade fiscal e o limite prudencial da folha (DOURADOS, 2015, p.39).

Porém, essas metas seguem aguardando o cumprimento, até então não efetivado. E, por fim, atendendo a meta 18 do PME, que garante a existência de planos de carreira para os profissionais da educação básica, destacamos as estratégias:

18.5 incentivar a participação de comissão eleita democraticamente pelo sindicato dos trabalhadores em educação, para contribuir com os órgãos competentes na elaboração, reestruturação e implementação dos planos de carreira, a partir da vigência deste PME;

18.6 garantir, sempre que houver a necessidade de abertura do concurso público, a participação da comissão organizadora paritária constituídas por servidores públicos municipais efetivos, representantes da Secretaria Municipal de Administração, da Secretaria Municipal de Educação, da Procuradoria Geral do município e do respectivo Sindicato da Classe, o qual deverá participar de todo o processo, desde a elaboração do edital até a posse;

18.10 fomentar o desenvolvimento de uma política de saúde específica para os profissionais da educação, que vise a prevenção e o tratamento de doenças, 
sobretudo relacionados à voz, visão, problemas vasculares, ergonômicos, psiquiátricos e psicológicos (DOURADOS, 2015, p.40).

As estratégias 18.5 e 18.6 foram parcialmente atendidas. Em relação à reestruturação dos planos de carreira foi formada uma equipe de representantes e. por meio de assembleia na câmara municipal de vereadores, deu-se início à proposta de reformulação do PCCR dos servidores públicos municipal.

Enfim, a Lei nº 3.904 (PME 2015-2025) engloba inúmeras maneiras de melhorar a qualidade do ensino público no município. Por se tratar de um documento construído democraticamente, aponta medidas segundo as especificidades locais, garantindo melhor desenvolvimento e aplicação prática das estratégias formuladas.

Com o exposto, fica evidente que a reformulação do PCCR no município de Dourados é tarefa que precisa ser realizada com urgência. Que seja debatido e construído pelos profissionais da educação e que sua construção seja reconhecida e referenciada pela Câmara dos Vereadores da cidade e assumida pela gestão desse município, pois somente assim será possível visualizar horizontes menos turvos quanto à valorização docente no município.

\section{Considerações finais}

A valorização profissional docente é marcada por lutas e embates que surtiram reaultados positivos a favor dos profissionais, por meio de medidas legais. Entretanto, alguns municípios ainda não cumprem o que determina a Lei, com direitos igualitários e melhores condições de vida e trabalho nas diferentes esferas da sociedade. Mas esse conjunto de reformas sociais está diretamente ligado às reformas educacionais, relacionando a melhoria da qualidade do ensino ao desempenho dos docentes.

O debate em torno da valorização trouxe avanços. que, entretanto, ainda esbarram em interesses políticos, que, na maioria das vezes, sobressaem em relação ao compromisso com a melhoria na qualidade do ensino e de trabalho do professor.

O município de Dourados enfrenta diversos desafios para a efetiva valorização dos profissionais do magistério. Além do exposto em relação à redução da jornada de trabalho, o número de professores não efetivos é muito grande, indo contra o que garante o próprio documento que rege a profissão - o PCCR.

O PCCR aponta a garantia de concurso público a cada dois anos, podendo ser prorrogados por mais dois, ou quando o quadro de contratados ultrapassar 20\% (vinte por cento), sendo que, no município, o quadro de professores contratados já ultrapassa $40 \%$ (quarenta por cento). 
Em relação ao concurso público, foi necessário o Ministério Público intervir para que ele fosse realizado. No entanto, ainda não há informações sobre as demais etapas, como chamada para prova de títulos, divulgação do resultado final, posse e outros segmentos legais do concurso.

Para além da questão salarial, registra-se uma luta em torno da redução da jornada de trabalho de 40 horas semanais para uma jornada de 20 horas semanais, sem redução do piso salarial profissional, caso em que se enquadra o município de Dourados.

Ainda segundo informações do site do sindicato, foram várias as tentativas de agendar um horário com o prefeito, para se chegar a um acordo, com o intuito de estabelecer uma proposta que atendesse as demandas e necessidades da categoria docente, sem causar danos orçamentários ao município, visto que o principal motivo da luta é a redução da jornada sem redução salarial.

Assim, percebe-se a importância do movimento grevista em busca da garantia por seus direitos. Embora tenha resultado em avanços relevantes, infelizmente, ainda percebemos que a educação pública municipal não é tratada como prioridade em termos de implementação de políticas públicas que venham, de fato, contribuir para a melhoria da qualidade do ensino no município, incluindo a valorização docente.

Finalizando, a relevância social e educacional deste estudo é a oportunidade de compreender que a qualidade da educação passa pela necessária "valorização docente". As lutas dos profissionais da educação de Dourados-MS mostram que é preciso buscar e lutar por questões que estão além da sala de aula (que é parte do processo educacional) e que tem estreita ligação com a qualidade e com a gestão democrática da educação.

Recebido em março de 2016 e aprovado em maio de 2016

\section{Notas}

1 Ainda existem muitos profissionais com formação em nível médio, com uma variação de sua renda salarial em relação aos profissionais com formação em nível superior, além da formação em programas de pós-graduação e progressão salarial.

2 Deste quantitativo de escolas estão inclusas todas as Etapas da Educação Básica (Educação Infantil, Ensino Fundamental e Ensino Médio) além da Modalidade Educação de Jovens e Adultos (EJA). 


\section{Referências}

ATLAS BRASIL. Índice de Desenvolvimento Humano Municipal - Dourados. Disponível em: <http:// www.atlasbrasil.org.br/2013/pt/ranking>. Acesso em: 21 abr.2016.

BRASIL. Lei no 9424, de 24 de Dezembro de 1996. Dispõe sobre o Fundo de Manutenção e Desenvolvimento do Ensino Fundamental e de Valorização do Magistério, na forma prevista no art.60, § 7.ำ do Ato das Disposições Constitucionais Transitórias, e dá outras providencias- Fundef. Brasília, 1996. Disponível em: <http://www.planalto.gov.br/ccivil_03/leis/L9424.htm>. Acesso em: 10 mar.2015.

Lei no 11.494, de 20 de Junho de 2007. Regulamenta o Fundo e desenvolvimento da Educação Básica e de Valorização dos Profissionais da Educação-Fundeb. Brasília, 2007. Disponível em: <http:// www.planalto.gov.br/ccivil_03/_ato2007-2010/2007/lei/111494.htm>. Acesso em: 10 mar. 2015.

Lei no 11.738, de 16 de Julho de 2008. Lei do Piso Salarial Profissional Nacional. MEC. Brasília, 2008. Disponível em: $<$ http://portal.mec.gov.br/index.php?option=com_content\&id=12253\&Itemid=86>. Acesso em: 30 jan.2015.

Lei no 13.005, de 25 de Junho de 2014 . Plano Nacional de Educação (2014-2024). MEC. Brasília, 2014. Disponível em: <http://pne.mec.gov.br/conhecendo-o-pne>. Acesso em: 26 fev.2015.

DORTA,Sireunise Camargo. História da educação em Dourados: criação da secretaria municipal de educação desafios e avanços na rede municipal de ensino 1977-1988. Dourados: Grupo literário Arandu. S/D. isbn 978-85-7965-044-4

DOURADOS. SIMTED. Sindicato Municipal dos Trabalhadores em Educação de Dourados. Página Oficial. Dourados, MS, 2016. Disponível em: <http://www.simted.org.br/noticias/professores-pedemretirada-de-processos-e-reconhecimento-da-junta>. Acesso em: 22 abr. 2016.

DOURADOS. Lei no 118, de 31 de dezembro de 2007. Dispõe sobre os planos de Cargos e Carreira. Dourados: Gabinete do Prefeito, 2007. Disponível em: <http://www.dourados.ms.gov.br/index.php/ lc-118_2007-pccr-dos-profissional-da-educacao-municipal-de-dourados-tabelas-de-2014-atualizadas/> Acesso em: 23 nov.2015.

Lei Complementar $\mathbf{n}^{0}$ 267, de 17 de Dezembro de 2014. Dispõe sobre a política salarial para os profissionais do Magistério Municipal na forma que menciona, e dá outras providencias. Dourados: Diário Oficial, 2015. Disponível em: <http://do.dourados.ms.gov.br/wp-content/ uploads/2015/01/08-01-2015.pdf . > Acesso em: 20 abr.2015.

Lei no 3.904, de 23 de Junho de 2015. Plano Municipal de Educação. Dourados, MS, 2015. Disponível em :<http://www.dourados.ms.gov.br/wp-content/uploads/2015/07/Lei-n\%C2\%BA-3904PME-Dourados-MS.pdf.> Acesso em: 20 out.2015.

Lei Complementar no 313, de 29 de Março de 2016. Reajuste do Piso Nacional 2016. Dourados: Diário Oficial, 2016. Disponível em: <http://do.dourados.ms.gov.br/wp-content/ uploads/2016/03/31-03-2016.pdf. > Acesso em: 15 abr.2016.

GATTI, Bernadete Angelina. Reconhecimento social e a políticas de carreira docente na Educação Básica. Cadernos de pesquisa, São Paulo.v.42, n.145, p.88-111.jan/abr.2012. Disponível em: <http:// www.scielo.br/pdf/cp/v42n145/07.pdf>. Acesso em 08 nov.2015.

GOUVEIA, Andrea Barbosa; TAVARES, Taís Moura. O magistério no contexto federativo: planos de carreira e regime de colaboração. Revista Retratos da Escola, vol.6, n.10, p. 185-197.jan/jun.2012. Disponível em :<http://www.esforce.org.br>. Acesso em : 12 mar.2015. 
IBGE. Instituto Brasileiro de Geografia e Estatística. Brasil, 2015.Disponível em:<http://www.cidades. ibge.gov.br/xtras/perfil.php?lang=\&codmun=500370>. Acesso em 14 abr. 2016.

INEP/MEC. Resumo técnico do Censo da Educação Superior. 2013. INEP/MEC, Brasília, 2013. Disponível em: <http://download.inep.gov.br/educacao_basica/censo_escolar/resumos_tecnicos/ resumo_tecnico_censo_educacao_basica_2013.pdf />. Acesso em: 05 abr. 2016.

VIEIRA, Juçara Dutra. Piso salarial nacional dos educadores: dois séculos de atraso. Brasília: CNTE,2007.

Piso salarial para educadores brasileiros: quem toma partido? . Campinas, SP: Autores Associados, 2013. 


\section{The appreciation of teaching, PSPN and PCCR* A study in the city of Dourados - MS}

ABSTRACT: This article deals with the appreciation of the teaching profession in the city of Dourados, MS, and seeks to analyze the policy of professional valuation in the current context, focusing on the Career Plan, Career and Remuneration and the National Professional Minimum Wage Law, through qualitative research on the body of documents composed of national and local items on the subject.

Keywords: Teaching salary. Educational policy. Career plans.

* Floor Wage National Professional Minimum Wage(PSPN)

Career Paths, Career and Remuneration Plan (PCCR)

\section{La valorisation des enseignants PSPN e PCCR* Une étude au sein de la ville de Dourados-état du Mato Grosso do Sul}

RÉSUMÉ: L'article traite de la valorisation du professionnel de l'enseignement au sein de la ville de Dourados-MS et cherche à analyser la politique de valorisation des professionnels dans le contexte actuel, en ciblant le Plan de Charges, Carrière et Rémunération et la Loi du Revenu Minimum Salarial National, par une recherche qualitative, avec un corpus documentaire composé de pièces nationales et municipales sur le théme.

Mots-clés: Salaire des enseignants. Politique éducative. Plan de carrière.

* Piso Salarial Profissional Nacional (PSPN): sigle correspondant au Revenu Minimum Salarial National

Plano de Cargos, Carreira e Remuneração (PCCR): Sigle correspondant au Plan de Charges, Carrière et Rémunération

\section{La valoración docente, MSPN y PCCR* Un estudio en el municipio de Dourados-MS}

RESUMEN: El artículo trata de la valoración de los profesionales docentes en el municipio de Dourados, en el estado de Mato Grosso do Sul (MS), con el objetivo de analizar la política de valoración de los profesionales en el contexto actual, centrando el foco en el Plan de Cargos, Carrera y Remuneración y la Ley del Mínimo Salarial Profesional, en encuesta cualitativa, cuyo corpus documental se ha constituido por fuentes nacionales y municipales sobre la cuestión.

Palabras clave: Salario docente. Política educativa. Plan de carrera.

* Mínimo Salarial Profesional Nacional (MSPN)

Plan de Cargos, Carrera y Remuneración (PCCR) 